\title{
Castleman's Disease Accompanied by Hypolipidemic Cerebral Hemorrhage and Nephrosclerosis
}

\author{
Aya Imafuku ${ }^{1}$, Tatsuya Suwabe ${ }^{1}$, Eiko Hasegawa ${ }^{1}$, Koki Mise ${ }^{1}$, Keiichi Sumida ${ }^{1}$, \\ Rikako Hiramatsu ${ }^{1}$, Masayuki Yamanouchi ${ }^{1}$, Noriko Hayami ${ }^{1}$, Junichi Hoshino ${ }^{1}$, \\ Naoki Sawa ${ }^{1}$, Kenichi Oohashi ${ }^{2}$, Takashi Fujii ${ }^{2}$, Minoru Okubo ${ }^{4}$, Kenmei Takaichi ${ }^{1,3}$, \\ Tatsuhide Oga $^{5}$ and Yoshifumi Ubara ${ }^{1,3}$
}

\begin{abstract}
A 56-year-old Japanese man developed a cerebral hemorrhage and was diagnosed with plasma cell-type multicentric Castleman's disease (MCD)based on the findings of an inguinal lymph node biopsy in addition to clinical findings, including hypergammaglobulinemia, anemia and elevation of the levels of CRP and serum IL-6. Although a renal biopsy showed nephrosclerosis, the levels of serum lipids and apolipoprotein were low. Following the initiation of treatment with anti-interleukin-6 receptor antibodies, the hypergammaglobulinemia, anemia, CRP level and serum lipid profile improved. However, inflammation due to overproduction of IL-6 persisted, and atherosclerotic vascular events occurred as critical complications, even though the serum levels of lipids were very low.
\end{abstract}

Key words: Castleman's disease, anti-interleukin-6 receptor antibody, tocilizumab, hypolipidemia, cerebral hemorrhage, nephrosclerosis

(Intern Med 52: 1611-1616, 2013)

(DOI: 10.2169/internalmedicine.52.0271)

\section{Introduction}

Multicentric Castleman's disease (MCD) is a lymphoproliferative disorder that features benign hyperplasia of lymph nodes characterized histologically by follicular hyperplasia and capillary proliferation with endothelial hyperplasia. The condition was first described by Castleman in 1956. MCD is classified into three types: the hyaline vascular type (80$90 \%)$, the plasma cell type (10-20\%) and the mixed type. Patients with the hyaline vascular type may exhibit no symptoms or have only lymphadenopathy, while patients with the plasma cell type or mixed type display various systemic manifestations, including fever, weight loss, anemia, hypoalbuminemia, hypergammaglobulinemia and increased levels of acute-phase proteins. Overproduction of interleukin-6 (IL-6) by germinal center B cells is considered to be the underlying cause of MCD. The prognosis of MCD has generally been reported to be poor, as chronic inflammation caused by the disease can result in critical complications, such as infection (e.g., pneumonia), renal failure (e.g., AA-amyloidosis and proliferative glomerulonephritis) or malignancy (e.g., non-Hodgkin's lymphoma and Kaposi's sarcoma) (1). Thus far, atherosclerotic events have not been reported to be complications of MCD. Nishimoto et al. demonstrated that a humanized anti-IL-6 receptor antibody (tocilizumab) is a therapeutic option for treating MCD (2). They reported that patients with MCD also have hypolipidemia that is markedly improved by tocilizumab therapy and stated that IL-6 overproduction plays a role in the etiology of this disease (3).

We encountered a patient with MCD who displayed atherosclerotic complications, including cerebral hemorrhage and renal dysfunction due to nephrosclerosis. The patient had a

\footnotetext{
${ }^{1}$ Nephrology Center, Toranomon Hospital, Japan, ${ }^{2}$ Department of Pathology, Toranomon Hospital, Japan, ${ }^{3}$ Okinaka Memorial Institute for Medical Research, Toranomon Hospital, Japan, ${ }^{4}$ Department of Endocrinology and Metabolism, Toranomon Hospital, Japan and ${ }^{5}$ Department of Rehabilitation, Toranomon Hospital, Japan

Received for publication February 3, 2013; Accepted for publication March 24, 2013

Correspondence to Dr. Yoshifumi Ubara, ubara@toranomon.gr.jp
} 
Table. Serum Lipid Profile

\begin{tabular}{|c|c|c|c|c|c|}
\hline \multirow{2}{*}{ Lipid markers } & \multirow{2}{*}{ normal range } & \multicolumn{3}{|c|}{ week } & rate of increase of \\
\hline & & 0 & 16 & 32 & lipids at \\
\hline Total-C (mg/dL) & $122-240$ & 89 & 178 & 194 & 117.9 \\
\hline HDL-C (mg/dL) & $35-70$ & 28 & 33 & 38 & 35.7 \\
\hline LDL-C (mg/dL) & $<140$ & 41 & 102 & 112 & 173.1 \\
\hline TG (mg/dL) & $30-150$ & 44 & & 158 & ND \\
\hline $\mathrm{FFA}(\mu \mathrm{Eq} / \mathrm{L})$ & $129-767$ & 209 & 224 & 537 & 156.9 \\
\hline $\mathrm{Lp}(\mathrm{a})(\mathrm{mg} / \mathrm{dL})$ & 4-25 & 1 & 5 & 2 & 100 \\
\hline $\mathrm{LCAT}(\mathrm{nmol} / \mathrm{mL} / \mathrm{hr})$ & $67.3-108.2$ & 32.3 & 64 & 93.7 & 190 \\
\hline apo-A I (mg/dL) & 119-155 & 72 & 114 & 127 & 76.3 \\
\hline apo-A II (mg/dL) & $25.9-35.7$ & 12.2 & 25 & 24.6 & 101.6 \\
\hline apo-B (mg/dL) & 73-109 & 41 & 93 & 100 & 143.9 \\
\hline apo-C II (mg/dL) & $1.8-4.6$ & 1 & 6.2 & 6.1 & 510 \\
\hline apo-C III (mg/dL) & $5.8-10.0$ & 3.7 & 10.3 & 10 & 170.2 \\
\hline apo-E (mg/dL) & $2.7-4.3$ & 2.6 & 4.8 & 5.3 & 103.8 \\
\hline non HDL-C & $<150$ & 61 & 145 & 156 & 155.7 \\
\hline apo-B/apo-A1 & unknown & 0.57 & 0.82 & 0.79 & 38.5 \\
\hline LDL-C/HDL-C & $<2.0$ & 1.5 & 3.1 & 3 & 100 \\
\hline
\end{tabular}

normal blood pressure and very low levels of serum lipids, such as total cholesterol (TC), LDL-cholesterol (LDL-C), HDL-cholesterol (HDL-C) and triglycerides (TG), accompanied by low levels of apolipoproteins (Apo-A1, A2 and $\mathrm{B} 100)$. The development of atherosclerotic lesions in patients with MCD is discussed from the perspective of chronic inflammation and lipid metabolism.

\section{Case Report}

We herein report the case of a 56-year-old Japanese man with MCD who developed hypolipidemia, a cerebral hemorrhage and nephrosclerosis. A low-grade fever, hypergammaglobulinemia and an elevated erythrocyte sedimentation rate (ESR) were noted in 1976; however, a definitive diagnosis was not made at the time. Treatment with prednisolone was initiated; however, it was soon discontinued due to lack of efficacy. In 1982, hypolipidemia and anemia were noted. In 2000, a dipstick urinalysis showed proteinuria. In 2005 , hypertension $(140 / 80 \mathrm{mmHg})$ was detected, and the patient's blood pressure was normalized with diet alone. In November 2009, a cerebral hemorrhage affecting the left putamen occurred without any precipitating cause, and surgical evacuation via craniotomy was performed at another hospital. In January 2010, the patient was admitted to our hospital for rehabilitation.

On admission, the patient was $171.0 \mathrm{~cm}$ in height and weighed $53.0 \mathrm{~kg}$, with a body mass index of $18.4 \mathrm{~kg} / \mathrm{cm}^{2}$. His blood pressure was $136 / 86 \mathrm{mmHg}$, his pulse rate was 96 beats/min and his temperature was $37.1^{\circ} \mathrm{C}$. The palpebral conjunctiva was pale. The lymph nodes in the right axilla and bilateral inguinal regions were palpable. Right hemiplegia and aphasia were apparent.

Laboratory tests showed a red blood cell count of $2.49 \times$ $10^{6} / \mu \mathrm{L}$, a hemoglobin level of $7.2 \mathrm{~g} / \mathrm{dL}$, a hematocrit level of $23.4 \%$, a leukocyte count of $3.9 \times 10^{3} / \mu \mathrm{L}$ and a platelet count of $23.3 \times 10^{4} / \mu \mathrm{L}$. Biochemistry tests revealed a total protein level of $11.2 \mathrm{~g} / \mathrm{dL}$, an albumin level of $1.6 \mathrm{~g} / \mathrm{dL}$, a urea nitrogen level of $30 \mathrm{mg} / \mathrm{dL}$, a creatinine level of 1.4 $\mathrm{mg} / \mathrm{dL}$, a C-reactive protein (CRP) level of $7.2 \mathrm{mg} / \mathrm{dL}$, an ESR of $>110 \mathrm{~mm} / \mathrm{h}$, a sodium level of $137 \mathrm{mmol} / \mathrm{L}$, a potassium level of $3.9 \mathrm{mEq} / \mathrm{L}$ and a chloride level of $104 \mathrm{mmol} /$ L. In addition, the aspartate aminotransferase (AST) level was $44 \mathrm{IU} / \mathrm{L}$, the alanine aminotransferase (ALT) level was $58 \mathrm{IU} / \mathrm{L}$ and the lactate dehydrogenase (LDH) level was 95 IU/L. The serum IgG level was $7,519 \mathrm{mg} / \mathrm{dL}$, the $\operatorname{IgA}$ level was $622 \mathrm{mg} / \mathrm{dL}$, the IgM level was $114 \mathrm{mg} / \mathrm{dL}$ and the IgG4 level was $1,770 \mathrm{mg} / \mathrm{dL}$. No M-proteins were detected. The IL-6 level was elevated to $15.4 \mathrm{pg} / \mathrm{mL}$ (normal <4.0), the vascular endothelial growth factor (VEGF) level was elevated to $260 \mathrm{pg} / \mathrm{mL}$ (normal <38.3) and the SAA level was elevated to $188 \mu \mathrm{g} / \mathrm{mL}$ (normal <8.0). The total cholesterol (TC) level was reduced to $90 \mathrm{mg} / \mathrm{dL}$ (normal range: 122 220), the LDL cholesterol (LDL-C) level was $42 \mathrm{mg} / \mathrm{dL}$ (normal <140), the HDL cholesterol (HDL-C) level was 42 $\mathrm{mg} / \mathrm{dL}$ (normal range: 35-70), the triglyceride (TG) level was $32 \mathrm{mg} / \mathrm{dL}$ (normal range: 30-150), the non-HDLcholesterol (TC-HDLC) level was 48 (target value $<150$ ), the lipoprotein(a) (lipo-a) level was decreased to $3 \mathrm{mg} / \mathrm{dL}$ (normal range: 4-25), the lecithin-cholesterol acyltransferase (LCAT) level was decreased to $32.3 \mathrm{U}$ (normal range: 67108), the apolipoprotein A1 (apo-A1) level was decreased to $72 \mathrm{mg} / \mathrm{dL}$ (normal range: 119-155), the apo-A2 level was decreased to $12.2 \mathrm{mg} / \mathrm{dL}$ (normal range: 25.9-35.7) and the apo-B100 level was decreased to $41 \mathrm{mg} / \mathrm{dL}$ (normal range: 73-109). The levels of Apo-C2, C3 and E were also low (Table). The urinary sediment contained less than 1 erythrocyte per high-power field (HPF), the level of 24-hr urinary protein excretion was $2.67 \mathrm{~g}$, the $\mathrm{N}$-acetyl- $\beta$-Dglucosaminidase (NAG) level was 54.0 IU and the $\beta 2$ microglobin level was $164 \mu \mathrm{g}$. The creatinine clearance was $42.8 \mathrm{~mL} / \mathrm{min}$ and the estimated GFR was $42.3 \mathrm{~mL} / \mathrm{min}$. Anti-HIV antibodies were negative, and no HHV-8 DNA was detected.

A chest radiograph showed an elongation of the thoracic aorta with a normal lung field. An electrocardiogram revealed left ventricular hypertrophy. Echocardiography demonstrated normal left ventricular contractions, although there 


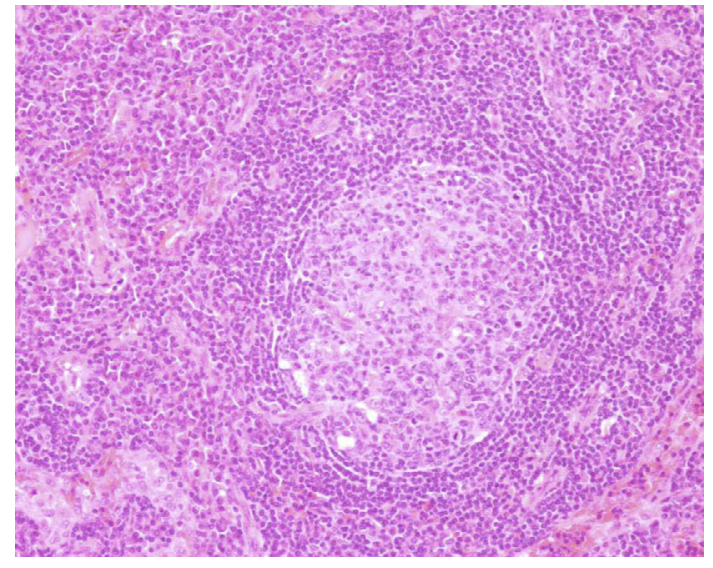

Figure 1. Inguinal lymph node biopsy findings. An inguinal lymph node biopsy revealed hyperplasia of the lymphoid follicles and infiltration of plasma cells between the follicles.

was calcification on the posterior mitral leaflet. Computed tomography (CT) disclosed lymph nodes measuring 2 to 3 $\mathrm{cm}$ in the right axilla and the bilateral inguinal regions. Bone marrow aspiration showed normocellular marrow with a slight increase in the level of plasma cells (5\% of nucleated cells), and the ratio of IgG4-positive to IgG-positive plasma cells was 20\%. PWV (pulse wave velocity)(Omron Colin) revealed a value of $1,686 \mathrm{~cm} /$ gram (normal: 1,126 to 1,486 ) on the right and $1,560 \mathrm{~cm} /$ gram on the left. CT showed elongation with calcification of the abdominal and thoracic aorta. Fundoscopy disclosed stage IIa disease according to the Keith-Wagener classification.

\section{Inguinal lymph node biopsy}

An inguinal lymph node biopsy revealed hyperplasia of the lymphoid follicles with prominent infiltration of plasma cells between the follicles (Fig. 1). IgG4-positive plasma cells accounted for approximately $30 \%$ of all IgG-positive plasma cells.

\section{Renal biopsy}

A percutaneous renal biopsy was performed on March 5, 2010. A light microscopic examination revealed 38 glomeruli, 13 of which exhibited global sclerosis. There was mild mesangial expansion and mild mesangial cell proliferation (Fig. 2a). The atrophic tubules demonstrated a patchy distribution, while inflammatory cells, including lymphocytes and plasma cells, had focally infiltrated the tubulointerstitium (Fig. 2b). IgG4-positive plasma cells accounted for approximately $25 \%$ of all IgG-positive plasma cells. The interlobular arteries exhibited mild fibroelastic intimal thickening (Fig. 2c); however, the arterioles displayed severe hyalinosis (Fig. 2d). All renal tissues, including the glomeruli, tubulointerstitium and small arteries, were negative for Congo red and amyloid A staining. Immunofluorescence was negative for immunoglobulin and complement. Electron microscopy showed only a slight increase in the amount of mesangial matrix without any electron-dense deposits or amyloid fibrils. A diagnosis of nephrosclerosis was made. A further biopsical examination of the duodenum and rectum as well as additional staining of the lymph nodes and bone marrow demonstrated negativity for Congo red staining.

\section{Clinical course}

Based on the patient's symptoms, laboratory findings (including elevation of the IL-6 level), histological features of the lymph nodes and exclusion of other conditions, such as infection, collagen diseases and malignant tumors, a diagnosis of MCD was made. The patient exhibited dysfunction due to both nephrosclerosis and cerebral hemorrhage. Treatment with an anti-IL-6 receptor antibody (tocilizumab) was initiated at a dose of $8 \mathrm{mg}$ fortnightly; however, the CRP level decreased to only $3.8 \mathrm{mg} / \mathrm{dL}$. After 18 weeks, the dose was increased to $8 \mathrm{mg}$ weekly hoping for further improvement. Various laboratory abnormalities, including elevation of the levels of CRP and ESR, hypoalbuminemia, anemia and hypergammaglobulinemia, all demonstrated improvement (Fig. 3). On January 2013, the serum creatinine level was $1.2 \mathrm{mg} / \mathrm{dL}$, the eGFR was $48.9 \mathrm{~mL} / \mathrm{min}$ and the $24-$ hour protein excretion was $0.49 \mathrm{~g}$. The levels of TC, LDL$\mathrm{C}$, LDL-C and TG increased to within the normal ranges. All levels of apolipoproteins (apoA-1, apoA-2, apoB-100, apoC-2, apoC-3 and apo-E) increased in correlation with the levels of serum lipids. The level of LDL-C demonstrated a more significant increase than that of HDL-C. The non-HDL cholesterol level, elevation of which is a known risk factor for cardiovascular atherosclerotic events, increased from 61 to 156 (Fig. 4, Table). The patient is doing well as of January 2013.

\section{Discussion}

Nishimoto et al. reported that most patients with MCD have low levels of TC, HDL-C, LDL-C and TG when the disease is active and that these lipid levels return to the normal ranges following treatment with tocilizumab (3). They suggested that overproduction of IL-6 may be responsible for the abnormal lipid levels and poor nutritional state observed in MCD patients due to chronic inflammation. Conditions that cause acute and chronic inflammation, such as infection, trauma and malignancy, are known to be associated with hypolipidemia $(4,5)$. Lipoprotein metabolism may be influenced by various inflammatory cytokines, in addition to IL-6, including IL-2, macrophage-colony stimulating factor (M-CSF), tumor necrosis factor- $\alpha$ (TNF- $\alpha$ ), interferon- $\alpha$ (IFN- $\alpha$ ), IFN- $\beta$ and IFN- $\gamma$ ) $(6,7)$. Hashizume et al. reported that injection of IL-6 into mice increases the VLDL receptor (VLDLR) expression in the heart, adipose tissue and liver and subsequently lowers the blood lipid levels, while injection of anti-IL-6 antibodies normalizes the low levels of TC and TG (8). Another recent study suggested that downregulation of VLDL-R in the heart mediated by IL- $1 \beta$ has an influence on cardiac lipid metabolism in mice with sepsis (9). VLDL-R binds to apo-E-containing particles, such as VLDL 


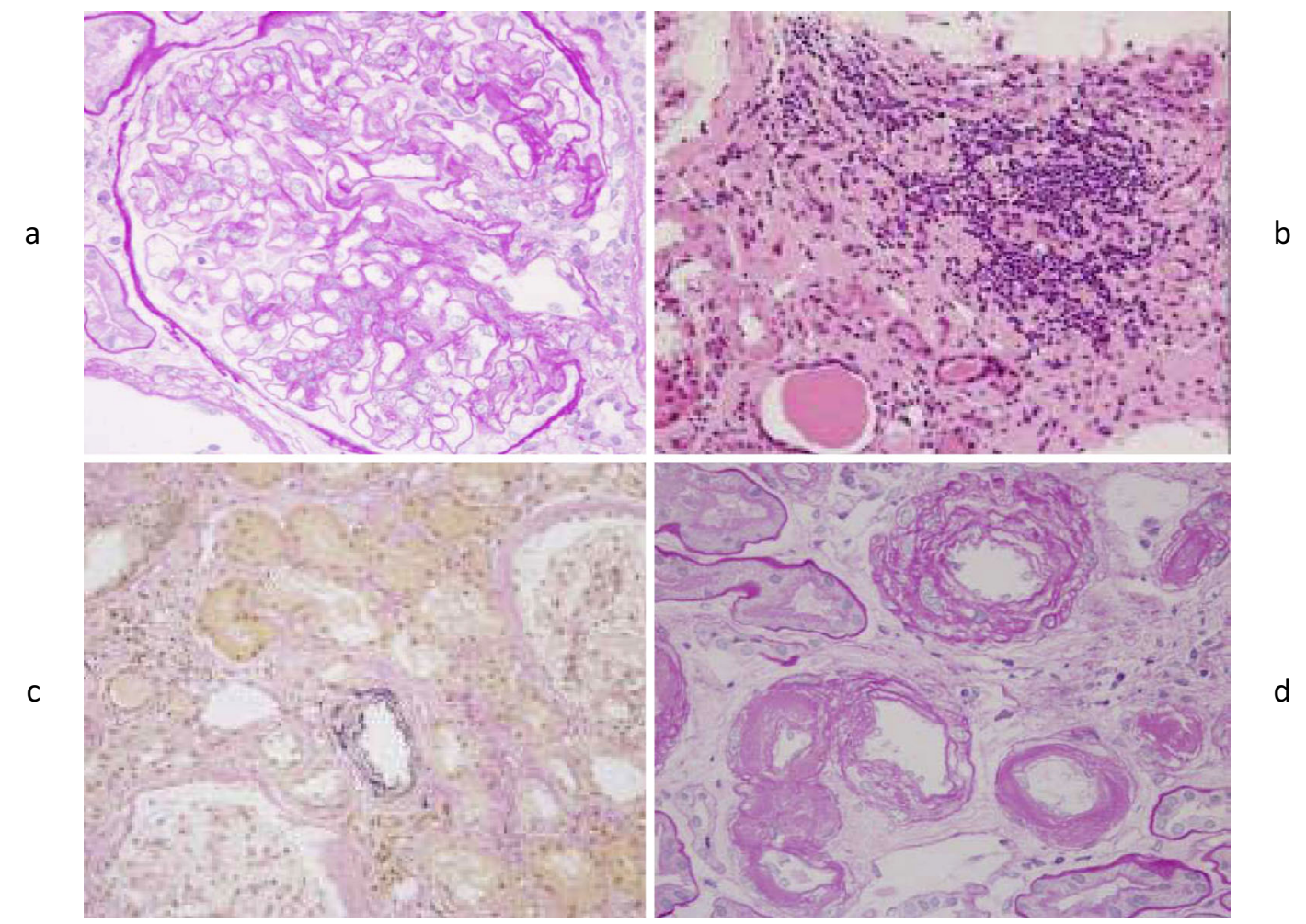

Figure 2. Renal biopsy findings. a) Mild mesangial expansion and mild mesangial cell proliferation. b) Mild infiltration of lymphocytes and plasma cells in the tubulointerstitial region. c) Mild fibroelastic intimal thickening of the interlobular arteries. d) Severe hyalinosis of the arterioles.
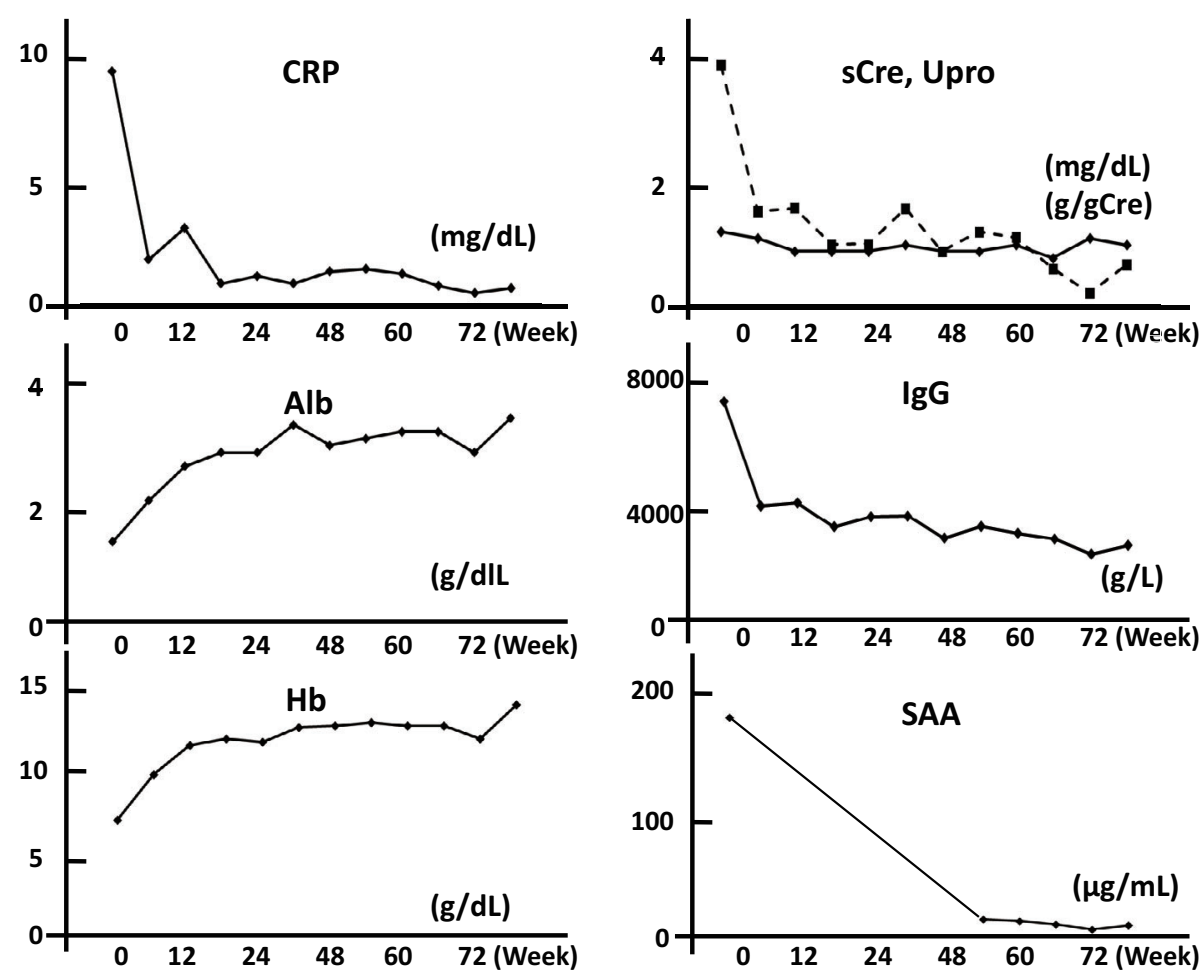

Figure 3. Changes in the levels of CRP, Alb, Hb, sCre, Upro, IgG and SAA.

and IDL, and may play a key role in regulating the blood levels of TC and TG, especially under inflammatory conditions. In this context, Ettinger et al. reported that injection of IL- 6 decreases the secretion of apo-A1 and apo-B100 by
HepG2 cells (10).

Cerebrovascular disease has not been reported in patients with MCD, although low serum lipid levels are recognized to be a possible risk factor for cerebral hemorrhage because, 

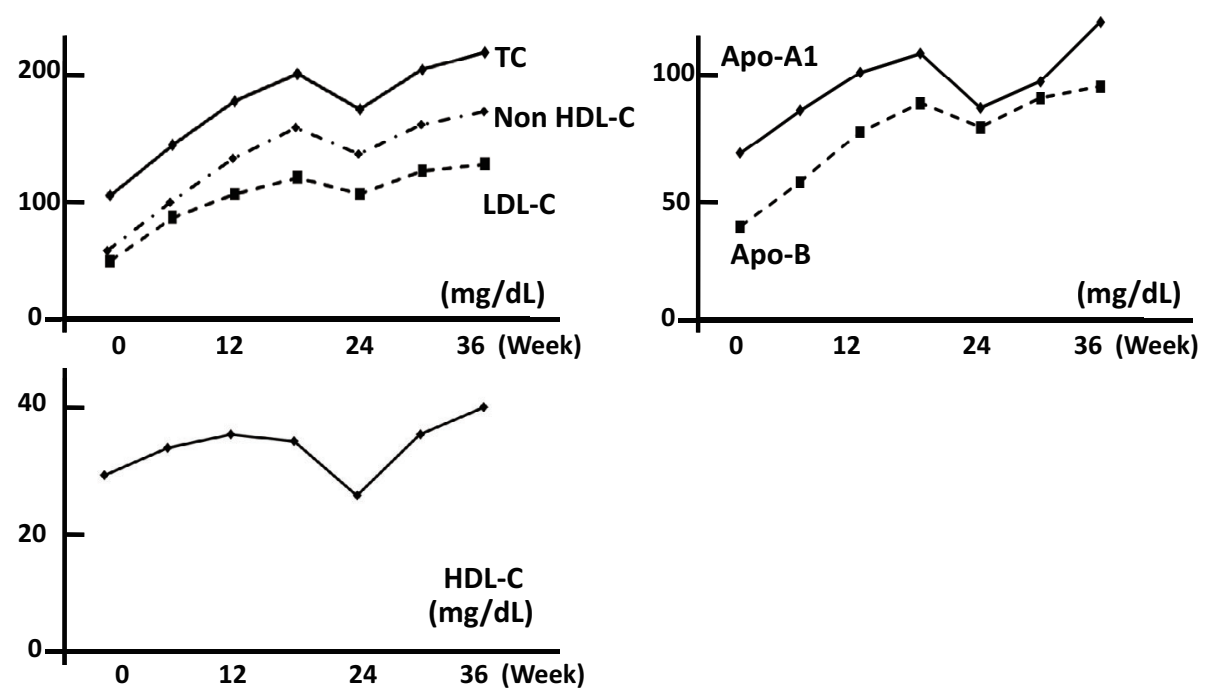

Figure 4. Changes in the levels of serum lipids.

under such conditions, the cerebrovascular endothelium becomes fragile and more vulnerable to leakage and rupture (11). Although it remains uncertain how various serum lipid components influence the risk of cerebral hemorrhage, recent evidence suggests that the incidence of cerebral hemorrhage may be primarily related to low TG levels rather than low HDL-C or LDL-C levels (12).

The renal involvement observed in patients with MCD is extremely variable, including secondary amyloidosis, minimal change disease, mesangial proliferative glomerulonephritis, membranous glomerulonephritis, membranoproliferative glomerulonephritis, interstitial nephritis and thrombotic microangiopathy (TMA)-like lesions (13). Recently, Karoui et al. summarized the renal histology of 19 patients with MCD. They reported that TMA-like lesions were most common (55-60\%), while lesions of secondary amyloidosis, the primary lesions in a previous report, accounted for only $20 \%$ of lesions (14). The authors also reported the presence of arteriosclerosis in 10 patients and arteriolar hyalinosis in 10 patients, both of which are consistent with nephrosclerosis (14).

Chronic inflammation related to elevations in the levels of cytokines, such as IL-6 and TNF- $\alpha$, contributes to the development of hypertension and nephrosclerosis in RA patients $(15,16)$ and is regarded to be a risk factor for cardiovascular disease (17).

In conclusion, we experienced a patient with MCD who developed hemorrhage and nephrosclerosis, even though almost all of his lipid levels (TC, LDL-C, HDL-C and TG) were low. The level of non-HDL-cholesterol, elevation of which is considered to be a risk factor for cardiovascular atherosclerotic events, was also low. Treatment with tocilizumab improved the patient's hypolipidemia as well as inflammatory markers related to MCD, such as the CRP level, anemia, hypoalbuminemia and hypergammaglobulinemia, and prevented the progression of renal dysfunction and pro- teinuria. Increased levels of apoA-1, A2 and B-100 were one of the causes of the increased levels of serum lipids. Continuous overproduction of IL-6 in patients with MCD may be related to atherosclerotic events by promoting chronic inflammation; however, the significance of the very low serum lipid levels observed in our patient remains unclear.

The authors state that they have no Conflict of Interest (COI).

\section{References}

1. Peterson BA, Frizzera G. Multicentric Castleman's disease. Semin Oncol 20: 636-647, 1993.

2. Nishimoto N, Sasai M, Shima Y. Improvement in Castleman's disease by humanized anti interleukin- 6 receptor antibody therapy. Blood 95: 56-61, 2000.

3. Nishimoto N, Kanakura $Y$, Aozasa $K$, et al. Humanized antiinterleukin-6 receptor antibody treatment of multicentric Castleman disease. Blood 106: 2627-2632, 2005.

4. Vermont CL, den Brinker M, Kâkeci N, et al. Serum lipids and disease severity in children with severe meningococcal sepsis. Crit Care Med 33: 1610-1615, 2005.

5. van Gameren MM, Willemse PH, Mulder NH, et al. Effects of recombinant human interleukin- 6 in cancer patients: a phase I-II study. Blood 84: 1434-1441, 1994.

6. Wilson DE, Birchfield GR, Hejazi JS, Ward JH, Samlowski WE. Hypocholesterolemia in patients treated with recombinant interleukin-2: appearance of remnant-like lipoproteins. J Clin Oncol 7: 1573-1577, 1989.

7. Schectman G, Schectman G, Kaul S, Mueller RA, Borden EC, Kissebah AH. The effect of interferon on the metabolism of LDLs. Arterioscler Thromb 12: 1053-1062, 1992.

8. Hashizume M, Yoshida H, Koike N, Suzuki M, Mihara M. Overproduced interleukin 6 decreases blood lipid levels via upregulation of very-low-density lipoprotein receptor. Ann Rheum Dis 69: 741-746, 2010.

9. Jia L, Takahashi M, Morimoto $\mathrm{H}$, et al. Changes in cardiac lipid metabolism during sepsis: the essential role of very low-density lipoprotein receptors. Cardiovasc Res 69: 545-555, 2006. 
10. Ettinger WH, Varma VK, Sorci-Thomas M, et al. Cytokines decrease apolipoprotein accumulation in medium from Hep G2 cells. Arterioscler Thromb 14: 8-13, 1994.

11. Konishi M, Iso H, Komachi $\mathrm{Y}$, et al. Associations of serum total cholesterol, different types of stroke, and stenosis distribution of cerebral arteries. The Akita Pathology Study. Stroke 24: 954-964, 1993.

12. Wieberdink RG, Poels MM, Vernooij MW, et al. Serum lipid levels and the risk of intracerebral hemorrhage: the Rotterdam Study. Arterioscler Thromb Vasc Biol 31: 2982-2989, 2011.

13. Leung KT, Wong KM, Choi KS, Chau KF, Li CS. Multicentric Castleman's disease complicated by secondary renal amyloidosis.
Nephrology (Carlton) 9: 392-393, 2004.

14. El Karoui K, Vuiblet V, Dion D, et al. Renal involvement in Castleman disease. Nephrol Dial Transplant 26: 599-609, 2011.

15. Panoulas VF, Metsios GS, Pace AV, et al. Hypertension in rheumatoid arthritis. Rheumatology (Oxford) 47: 1286-1298, 2008.

16. Boers M, Croonen AM, Dijkmans BA, et al. Renal findings in rheumatoid arthritis: clinical aspects of 132 necropsies. Ann Rheum Dis 46: 658-663, 1987.

17. Aubry MC, Maradit-Kremers H, Reinalda MS, Crowson CS, Edwards WD, Gabriel SE. Differences in atherosclerotic coronary heart disease between subjects with and without rheumatoid arthritis. J Rheumatol 34: 937-942, 2007.

(C) 2013 The Japanese Society of Internal Medicine http://www.naika.or.jp/imonline/index.html 